\title{
Analysis of a pneumatic system for a two-phase flow sugar
}

\author{
Gustavo J. Otero R.', Geanette Polanco² \\ and Miguel Asuaje ${ }^{3}$ \\ 1Universidad Simón Bolívar, Laboratorio de Conversión de Energía \\ Mecánica, Valle de Sartenejas, Venezuela, gustavojoteror@gmail.com \\ ¿Universidad Simón Bolívar, Departamento de Mecánica de Fluidos, Valle \\ de Sartenejas, Venezuela, gpolanco@usb.ve \\ 3Universidad Simón Bolívar, Departamento de Conversión y Transporte \\ de Energía, Valle de Sartenejas, Venezuela, asuajem@usb.ve
}

\begin{abstract}
This document shows a complete analysis the transportation of sugar particles by a pneumatic conveying station. This project shows an actual situation presenting in a food plant located in Aragua, Venezuela, where the sugar piping system suffers continuous obstructions. It was achieved an effective analysis of the phenomenon of solid-gas two-phase flow transport which involves a complex physics phenomenon. Two possible obstruction causes was studied: the high temperature at the blower exit that induces changes in the sugar properties caused by the working condition far from the designed operation condition, or the excessive friction losses, due to the system is working out of the dilute phase condition (optimal condition for the flow). The mathematical model described allowed to determine that the cause of the obstruction of the pipeline was the stick of the sugar to the internal wall, as consequence of this high temperature at the outlet of the blower.
\end{abstract}

Keywords: pneumatic system, two-phase flow, solid-gas pressure drop

\section{NOMENCLATURE}

LATIN SYMBOLS

$A \quad$ Pipe Area $\left(\mathrm{m}^{2}\right)$

$B \quad$ Bend Loss Coeficient (-)

$D \quad$ Pipe Diameter (m)

$d_{p} \quad$ Diameter of the Particle (m)

$d_{p}^{*} \quad$ Critical Diameter of the Particle $(\mathrm{m})$

$F_{r}{ }^{p} \quad$ Froude Number (-)

$\mathrm{Fr}_{s s} \quad$ Solids in Saltation Froude Number (-)

$g \quad$ Accelaration due to gravity $\left(9,807 \mathrm{~m} / \mathrm{s}^{2}\right)$

GE Especific Gravity (-)

$k_{s} \quad$ Pipe Roughness(m)

K Constant

$L \quad$ Pipe Lenght (m)

$\dot{m}_{a} \quad$ Mass flow of the phase " $a$ " $(\mathrm{kg} / \mathrm{s})$ 
$R_{b} \quad$ Bend Radius (m)

$R_{e} \quad$ Reynolds Number (-)

$U \quad$ Velocity $(\mathrm{m} / \mathrm{s})$

$U_{b} \quad$ Chocking Velocity $(\mathrm{m} / \mathrm{s})$

$U_{\text {salt }} \quad$ Saltation Velocity $(\mathrm{m} / \mathrm{s})$

$U_{t} \quad$ Slip velocity $(\mathrm{m} / \mathrm{s})$

$\dot{V}^{t} \quad$ Volumetric Flow $\left(\mathrm{m}^{3} / \mathrm{s}\right)$

$z \quad$ Solids Loading $(-)$

$Z_{\text {salt }} \quad$ Saltation Solid Loading (-)

\section{GREEK LETTERS}

$\Delta P_{a c c} \quad$ Acceleration of the Solid Pressure Drop (Pa)

$\Delta P_{\text {bends }}$ Pressure Drop in Bends $(\mathrm{Pa})$

$\Delta P_{\text {feeder }}$ Feeders Pressure Drop $(\mathrm{Pa})$

$\Delta P_{\text {fric }}$ Friction Pipeline Pressure Drop $(\mathrm{Pa})$

$\triangle P_{M A} \quad$ Blower Pipping and Feed Section Pressure Drop (Pa)

$\Delta P_{\text {separ }}$ Pressure Drop on the Phase Separator $(\mathrm{Pa})$

$\Delta P_{\text {sta }}^{\text {separ }}$ Static Pressure Drop $(\mathrm{Pa})$

$\Delta Z \quad$ Height Diferential (m)

$\varepsilon \quad$ Voidage $(-)$

$\lambda \quad$ Friction factor $(-)$

$\rho \quad$ Density $\left(\mathrm{kg} / \mathrm{m}^{3}\right)$

$\mu \quad$ Cinematic Viscosity $(\mathrm{kg} / \mathrm{m} . \mathrm{s})$

\section{SUBSCRIPTS}

$g \quad$ Gas Phase

p Particle

$s \quad$ Solid Phase (Bulk Solids)

\section{INTRODUTION}

Using gas for the movement of suspended particles is not a novel idea, as far as the food industry is concerned. Most of the raw materials in powder form (sugar, milk powder, etc) used in the mixtures at the factory are transported from the general storing warehouse to the production lines of the plant coexisting solid and gaseous phases within the pneumatic conveying systems [1].

The food factory where the project was held produces goods such as chocolates, chewing gum, cookies, candies, and wafer, and then they are distributed throughout the country (Venezuela). It is obvious that the main ingredient of most of these products is sugar. It is therefore of vital importance that the sugar can be transported efficiently and quickly throughout the factory and with the minimum possible losses. A problem with the supply of sugar would affect the entire factory.

\section{PROBLEM STATEMENT}

The problem with the pneumatic transport system in the factory is a concurrent blockage of the pipeline, which feed all the production areas, causing long downtimes in the production lines and waste of sugar. 


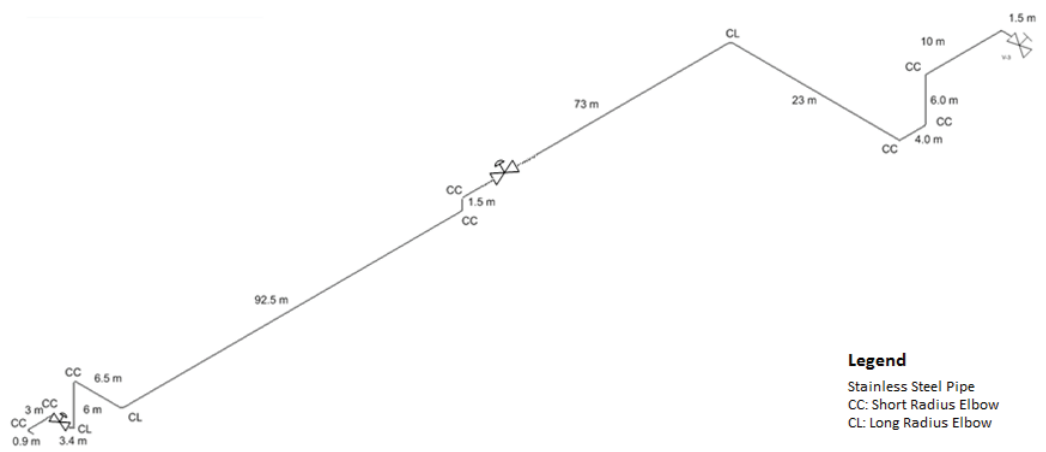

Figure 1 Isometric of the pneumatic conveying pipeline

The current pipeline consists of a long pipeline (about 200 meters) with numerous accessories (elbows and directional valves), as shown in Figure 1. This system is equipped with a blower (GM Aerzen 25S), a rotary valve (Buhler MPSH 22/22) and a cyclone separator (MVRS Buhler) with bag filter (Buhler SVRL).

\section{REVIEW}

The solid-gas flow in pipes is classified in dilute phase flow (suspended particles dragged by gas) and dense phase flow (particle flow by waves or dunes). Different flow patterns can be produced in a solid-gas flow. Depending on the pattern flow is at; pressure, velocity, force and vibrations are different.

In a solid-gas flow it can be identified 10 progression patterns as the gas velocity decreases [2]. The first three patterns are known as dilute phase transport patterns, where the system can operates under optimum conditions. Diluted Phase Transport refers to the type of pneumatic transport where all the particles are fully entrained in the gas phase. The velocity difference between the gas and the particles (slip velocity) promotes the driving force that makes possible the dragging of the solid phase.

From dilute phase transport patterns to onward begins the nonsuspension flow, the dunes formation and the transition period to a dense phase conveying. It is possible to work on this type of pattern but not an optimal condition. Until the pipe is almost totally covered by the solids in suspension and finally, the pattern 10 is when the pipe is totally obstructed [2].

Knowing the flow pattern is easy to identify what kind of transport is the mixture working at (dilute and dense), however, it is too complicate to find out in the other way around. For this reason it was necessary to create correlations that provide a diagram (phase) where it is displayed the behavior of the flow depending on certain variables; the pressure gradient, superficial gas velocity and solid loading of the flow. The gas-particle interaction generates a pressure drop; therefore it is more complicated to boost a solid-gas flow than a single gas flow. Figure 2 shows a typical phase diagram of a solid-gas flow. The two regions that can be observed in the curve are divided by a velocity called "saltation". This is the velocity where the solid particles begin to decay because the lift and drag forces produced by the gas can no longer sustain them. These two regions are for dense phase transport and dilute phase. The mass flow of the solid (solid loading) is an important variable for transporting solid gas, in most of the cases defines the size of the system [2]. 


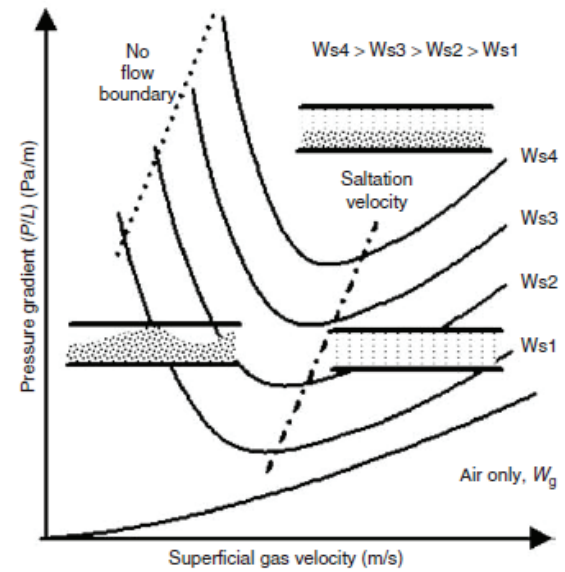

Figure 2 Flow patterns in a solid-gas flow

To analyze a solid-gas flow it is necessary to establish the velocity of each entity involved. The gas velocity is modeled by assuming that the gas fills the entire cross-sectional area of the pipe [2]:

$$
\mathrm{U}_{\mathrm{g}}=\frac{\dot{\mathrm{V}}_{\mathrm{g}}}{\mathrm{A}}
$$

The particle velocity can be calculated with the Modified Hinkle correlation, where the diameters (particle and pipe) must be in meters (m) while the densities (particle and gas) in kilograms per cubic meter $\left(\mathrm{kg} / \mathrm{m}^{3}\right)[2]$ :

$$
\mathrm{U}_{\mathrm{p}}=\mathrm{U}_{\mathrm{g}}\left(1-0.68 \mathrm{~d}_{\mathrm{p}}^{0.92} \mathrm{D}^{-0.54} \rho_{\mathrm{p}}^{0.5} \rho_{\mathrm{g}}^{-0.2}\right)
$$

Finally, the slip velocity can be calculated as the difference between the velocities of each phase.

$$
\mathrm{U}_{\mathrm{t}}=\mathrm{U}_{\mathrm{g}}-\mathrm{U}_{\mathrm{p}}
$$

\subsection{SALTATION}

When designing a solid-gas transport it is important to know in which stage to carry out the transport (dilute or dense). This requires knowing the saltation velocity. It is customary to use the saltation velocity as the operation velocity (with a safety factor) due to the low power consumption, minimum erosion, low pressure gradient and little degradation of the particle, and of course it avoid to the particles begin to fall in the surface of the pipe [3]. The saltation velocity can be estimated with Matsumoto correlation, which can only be used if the specific gravity of the particle, , is greater than 3 . This correlation is based on the fact that gross and 
fine particles behave different.

$$
\mathrm{GE}=\frac{\rho_{\mathrm{p}}}{\rho_{\text {water }}}
$$

The solid loading of saltation $\left(\mathrm{z}_{\text {salt }}\right)$ is defined by saltation velocity and velocity written in function of mass flow, density and the area to have the gas mass flow at the point of saltation [2]. Before using this correlation the critical particle diameter, $\mathrm{d}_{\mathrm{p}}^{*}$, must be calculated [2]:

$$
\begin{aligned}
& \mathrm{d}_{\mathrm{p}}^{*}=1.39 \mathrm{D}\left(\frac{\rho_{\mathrm{p}}}{\rho_{\mathrm{g}}}\right)^{-0.74} \\
& z_{\text {salt }}=\left\{\begin{array}{cc}
0.373\left(\frac{\rho_{\mathrm{p}}}{\rho_{\mathrm{g}}}\right)^{-0.74}\left(\frac{\mathrm{Fr}}{10}\right)^{-3.7}\left(\frac{\mathrm{Fr}}{10}\right)^{3.61} & \text { for } \mathrm{d}_{\mathrm{p}} \geq \mathrm{d}_{\mathrm{p}}^{*} \\
55\left(\frac{\mathrm{d}_{\mathrm{p}}}{\mathrm{D}}\right)^{1.43}\left(\frac{\mathrm{Fr}}{10}\right)^{4.0} & \text { for } \mathrm{d}_{\mathrm{p}}<\mathrm{d}_{\mathrm{p}}^{*}
\end{array}\right.
\end{aligned}
$$

where:

$$
\begin{aligned}
& \mathrm{Fr}_{\mathrm{p}}=\frac{\mathrm{U}_{\mathrm{t}}}{\sqrt{\mathrm{gd}_{\mathrm{p}}}} \\
& \mathrm{Fr}_{\mathrm{ss}}=\frac{\mathrm{U}_{\text {salt }}}{\sqrt{\mathrm{g} \mathrm{D}}}
\end{aligned}
$$

\subsection{CHOKING VELOCITY}

Choking velocity is the minimum speed before the pipe is covered completely by bulk solids. Therefore the choking velocity provides the minimum limit at which a pneumatic conveying system can operate. Using Chong and Leung correlation [2] it is possible to estimate the choking velocity as:

$$
\mathrm{U}_{\mathrm{b}}=32 \sqrt{\mathrm{gd}_{\mathrm{p}}} \operatorname{Re}_{\mathrm{p}}^{-0.06} \mathrm{z}^{0.28}
$$

where:

$$
\operatorname{Re}_{\mathrm{p}}=\frac{\rho_{\mathrm{g}} \mathrm{U}_{\mathrm{t}} \mathrm{d}_{\mathrm{p}}}{\mu_{\mathrm{g}}}
$$




\subsection{PRESSURE DROP CALCULATION FOR A DILUTE PHASE SYSTEMS}

The pressure drop of the gas in the pneumatic system can be estimated with standard methods used in one phase flow, including pressure drop due to accessories and including aspects of the two-phase flow motion, as follows:

The acceleration pressure drop

The acceleration pressure drop is due to the additional energy needed to accelerate the solid and thus achieving steady-state speed.

$$
\mathrm{P}_{\mathrm{acc}}=\frac{\rho_{\mathrm{g}} \mathrm{U}_{\mathrm{g}}^{2}}{2}\left(1+2 \mathrm{z}\left(\frac{\mathrm{U}_{\mathrm{p}}}{\mathrm{U}_{\mathrm{g}}}\right)\right)
$$

The static component of the pipeline pressure drop

For the static pressure drop involves the effects of the void fraction, :

$$
\begin{aligned}
& \varepsilon=1-\frac{\dot{\mathrm{m}}_{\mathrm{s}}}{\mathrm{A} \rho_{\mathrm{p}} \mathrm{U}_{\mathrm{p}}} \\
& \mathrm{P}_{\text {sta }}=\rho_{\mathrm{p}}(1-\varepsilon) \quad \mathrm{Zg}+\varepsilon \rho_{\mathrm{g}} \quad \mathrm{Zg}
\end{aligned}
$$

The friction components of the pipeline pressure drop

For the friction component is necessary to define the friction factors of both phases:

$$
\lambda=\left\{\begin{array}{cc}
\frac{1,325}{\left[\ln \left(\mathrm{k}_{\mathrm{s}} / 3,7 \mathrm{D}+5,74 / \mathrm{Re}^{0.9}\right)\right]^{2}} & \text { for gas } \\
\mathrm{K} \mathrm{z}^{\mathrm{a}} \operatorname{Fr}_{\mathrm{g}}^{\mathrm{b}} \operatorname{Fr}_{\mathrm{s}}^{\mathrm{c}}\left(\frac{\mathrm{D}}{\mathrm{d}_{\mathrm{p}}}\right)^{\mathrm{d}} & \text { for solid }
\end{array}\right.
$$

where:

$$
\begin{aligned}
& \mathrm{Re}=\frac{\mathrm{U}_{\mathrm{g}} \mathrm{D} \rho_{\mathrm{g}}}{\mu_{\mathrm{g}}} \\
& \mathrm{Fr}_{\mathrm{s}}=\frac{\mathrm{U}_{\mathrm{t}}^{2}}{\mathrm{gd}_{\mathrm{p}}}
\end{aligned}
$$

The exponents of the equation $13 \mathrm{a}, \mathrm{c}$ and $\mathrm{d}$ keep their values for all particles sizes, $\mathrm{a}=-0.30$, $\mathrm{c}=0.25$ and $\mathrm{d}=0.10$. However, the coefficients $\mathrm{K}$ and $\mathrm{b}$ depend on the size of the particle. For fine powder $\left(d_{p}<0.5 \mathrm{~mm}\right) \mathrm{K}=2.10$ and $\mathrm{d}=-1.00$, meanwhile, for coarse material $\left(d_{p}>\right.$ $0.5 \mathrm{~mm}) \mathrm{K}=0.082$ and $\mathrm{b}=-0.86[4]$. 
Finally, the pressure drop by friction in the pipe can be calculated as:

$$
\mathrm{P}_{\text {fric }}=\lambda_{\mathrm{g}} \frac{\rho_{\mathrm{g}} \mathrm{U}_{\mathrm{g}}^{2} \mathrm{~L}}{2 \mathrm{D}}+\left(\mathrm{z} \lambda_{\mathrm{s}}\right) \frac{\rho_{\mathrm{g}} \mathrm{U}_{\mathrm{g}}^{2} \mathrm{~L}}{2 \mathrm{D}}
$$

\section{Pressure drop in bends}

The pressure drop in bends has a great deal of importance in pneumatic system due to its magnitude. It is produced by the reacceleration of the solid particles and the change of direction.

$$
P_{\text {bends }}=B(1+z) \frac{\rho_{g} U_{g}^{2}}{2}
$$

where " $\mathrm{B}$ " is the bend loss coefficient (Table 1), which depends on the ratio of bend radius to pipe diameter.

Table 1 Bend loss coefficient for various bends [8]

\begin{tabular}{|l|l|l|l|}
\hline $\boldsymbol{R}_{\boldsymbol{b}} / \boldsymbol{D}$ & 2 & 4 & $\ddagger 6$ \\
\hline $\boldsymbol{B}$ & 1.50 & 0.75 & 0.50 \\
\hline
\end{tabular}

Pressure in other elements of the system

The pressure drop in the feeder of solid phase ( and in the separator ( depends on the flow of gas and solids loading, these values are referred by the supplier.

Total pressure drop of the system

The total pressure gradient of the pneumatic system must counter all the other pressure drops. The energy required, $\Delta P$, to overcome those losses must be supplied by the blower.

$$
P=P_{a c c}+P_{\text {sta }}+P_{\text {fric }}+P_{\text {bends }}+P_{\text {feeder }}+P_{\text {separ }}
$$

\section{PNEUMATIC CONVEYING SYSTEM}

\subsection{SURVEY DATA}

Sugar requirements

The consumption of sugar is assumed to be the total requirement of the factory, which is $2560 \mathrm{~kg} / \mathrm{hr}$. However, due to this system is not really blowing sugar this entire quantity by an hour. The requirement was modeled for half of the time (30 minutes), to thereby consider sweeping time and stoppage time of the pneumatic system. Thus the requirement for total sugar is $5120 \mathrm{~kg} / \mathrm{hr}$. 


\section{Material properties and operation conditions}

Sugar samples were taken from sugar bags currently in use were test in the laboratory. Physical-chemical tests were made to determine three properties: particle density, moisture from the sample and the particle diameter, all three shown in Table 2.

Table 2 Properties of sugar

\begin{tabular}{lr}
\hline Density & $855.1 \mathrm{~kg} / \mathrm{m}^{3}$ \\
\hline Moisture & $0.03 \%$ \\
\hline Diameter of the Particle & $54 \%$ of the grains $>500 \mu \mathrm{m}$
\end{tabular}

For the calculations, it was necessary to assume an approximate diameter of the particle of 501 microns, since by making the particle size with a sieve of $500 \mu \mathrm{m}$ which retained an average of $54 \%$ sugar is impossible to estimate an exact diameter value in the laboratory.

Environmental conditions average values and air properties [5] are presented in Table 3:

Table 3 Conditions and properties of the air

\begin{tabular}{lc}
\hline Temperature [...C] & 33 \\
\hline Pressure[kPa] & 101.33 \\
\hline Relative Humidity [\%] & 70 \\
\hline Density [kg/m $\left.{ }^{3}\right]$ & 1.138 \\
\hline Viscosity $[\mathrm{kg} / \mathrm{m} . \mathrm{s}]$ & $1.87 \mathrm{E}-05$ \\
\hline
\end{tabular}

\section{Loss coeficients}

It was assumed that the loss factors in valves are the same with two-phase flow and with just air flow frequently used [6]. It was also estimated the roughness of the pipe depending on the material, which applies for both flows.

\subsection{ANALYSIS OF THE PNEUMATIC CONVEYING SYSTEM}

The initial analysis of the pneumatic system suggests that for solving the problem of clogging of the pipe of sugar it is necessary to identify the actual source of the problem. There were two starting hypothesis to be developed:

1. It was thought that the losses in the pipeline were excessive because of the long distance and the great number of accessories making the flow rate reaches its lock.

2. The environmental conditions of temperature and relative humidity could cause the sugar to caramelize, sticking itself to the pipeline until it finally obstructs the flow. 
Components of the pneumatic conveying system

The technical specifications of the blower Aerzen GM 25S are shown in Table 4.

Table 4 Technical data for the blower Aerzen GM 25S

\begin{tabular}{lcc}
\hline Model & GM 25S a & GM 25S b \\
\hline Angular Velocity & $4090 \mathrm{rpm}$ & $4800 \mathrm{rpm}$ \\
\hline Volumetric Flow of Air & $19.5 \mathrm{~m}^{3} / \mathrm{min}$ & $23.5 \mathrm{~m}^{3} / \mathrm{min}$ \\
\hline Pressure Delta & 1 (bar) & 1 (bar) \\
\hline Outlet Temperature & $121 \ldots \mathrm{C}$ & $118 \ldots \mathrm{C}$ \\
\hline Engine Power & $55 \mathrm{~kW}$ & $55 \mathrm{~kW}$ \\
\hline
\end{tabular}

The blower has a variable frequency drive thus able to operate at two speeds which provides a couple of gas flow rates. Figure 3 and Figure 4 show the characteristic curves of the positive displacement blower Aerzen GM 25S, which has two rotary lobes.

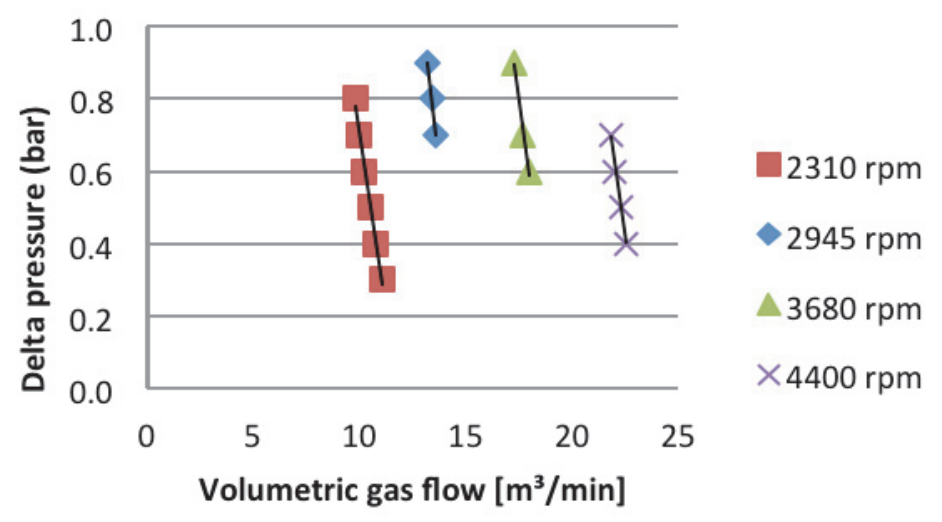

Figure 3 Characteristic delta pressure vs. volumetric gas flow curve of the blower GM 25S

To achieve higher pressure the blower needs to increase the torque therefore generating heat in the blower. Having the same pressure differential gas exits the blower achieves at least $2 \%$ higher temperature when it rotates at lower speed, as it is shown in Figure 4. For example with a differential pressure of 0.8 (bar) there is 6 degrees increase between the blower rotating at $2945 \mathrm{rpm}$ and $2310 \mathrm{rpm}$. In this case 6 degrees is no significant but when operating above 1 (bar) this temperature increase will be greater. 


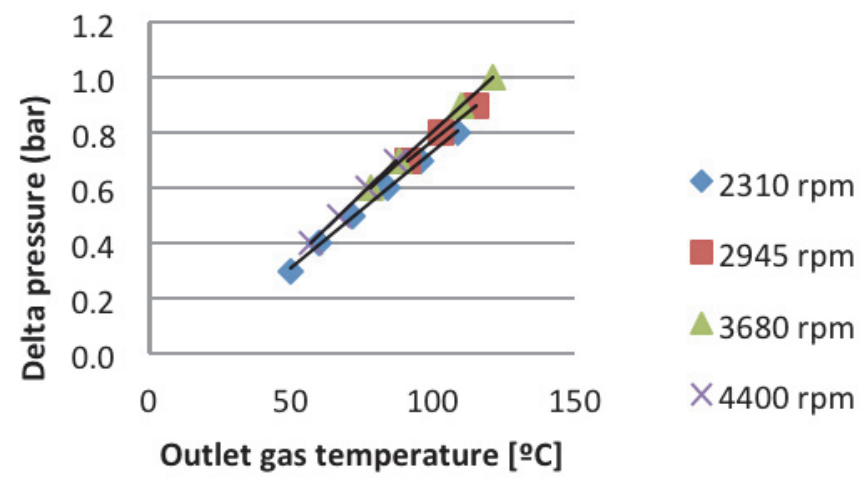

Figure 4 Characteristic delta pressure vs. outlet gas temperature curve of the blower GM 25S

The rotary valve model Buhler MPSH is able to rotate at different speeds and provide different mass flow rates of solids. For this case the rotary valve MPSH 22/22 has a capacity of $0.23\left(\mathrm{ft}^{3}\right)$ per revolution. Table 5 shows the capacity of sugar per hour offered by this airlock.

Table 5 Rotary valve MPSH 22/22 Capacity

\begin{tabular}{cc}
\hline Angular velocity (rpm) & Sugar Mass flow $[\mathrm{kg} / \mathrm{hr}]$ \\
\hline 10 & 2673 \\
\hline 15 & 4010 \\
\hline 20 & 5346 \\
\hline 25 & 6683 \\
\hline 30 & 8020 \\
\hline
\end{tabular}

Taking a volumetric efficiency of $80 \%$

The behavior of the mass flow of sugar through the airlock MPSH 22/22 or any other rotary valve is directly proportional to the rotational speed and its volumetric capacity. It is clear that if there is more space or a faster rotation of the cavities, more sugar will cross the rotary valve. With the airlock MPSH 22/22 rotating at $20 \mathrm{rpm}$ is possible to achieve the requirement of sugar calculated $(5120 \mathrm{~kg} / \mathrm{hr})$.

Depending on the receiving station, the cyclone separator of gas and solid will be different in size but the operation will be the same. The cyclone separator MVRs Buhler has two functions in the system: the primary function as a separator; remove air from the sugar with the help of SVRL Buhler bag house, and serve as feeder lung of sugar to the production area to which it belongs. 


\section{Calculation of pressure drop in the pneumatic conveying system}

The pressure drop calculations are an estimate of what actually happens in the pipeline. All flows are related to the blower inlet conditions according to the manufacturer ( 1 (bar), $20^{\circ} \mathrm{C}$ and air density $1.2 \mathrm{~kg} / \mathrm{m}^{3}$ ). To carry out all the calculations it was necessary to make several assumptions:

- All along the pipeline the flow is fully developed.

- $\quad$ Fluid properties are constant.

- Steady-state conditions apply.

- $\quad$ All solid particles are of same size and shape.

- $\quad$ Particle diameter of $501 \mu \mathrm{m}$.

- No wear of the sugar particle.

- Loss factor of the rotary valve of 2 .

- $\quad$ Pressure drop in the solids separator of $2000 \mathrm{~Pa}$ [7].

For this estimation it was first necessary to know in what phase of transport the flow was in, that way be able to define the type of model to apply. It was needed to calculate the saltation volumetric flow and compared with the air flow provided by the blower. The first correlation of Matsumoto was used for this calculation, given that the specific gravity is greater than 3 and that the particle diameter is greater than the particle critical diameter. Table 9 shows the flow rates of saltation calculated for each of the angular velocities offered by the existing airlock.

Table 6 Saltation volumetric flow for rotary valve 22/22

\begin{tabular}{cc}
\hline Angular velocity & Saltation volumetric flow $\left[\mathrm{m}^{3} / \mathrm{min}\right]$ \\
\hline $10 \mathrm{rpm}$ & 2.048 \\
\hline $15 \mathrm{rpm}$ & 2.169 \\
\hline $20 \mathrm{rpm}$ & 2.258 \\
\hline $25 \mathrm{rpm}$ & 2.330 \\
\hline $30 \mathrm{rpm}$ & 2.391 \\
\hline
\end{tabular}

As shown on Table 6, the saltation volumetric flow of the existing system varies between 2.0 $\mathrm{m}^{3} / \mathrm{min}$ and $2.4 \mathrm{~m}^{3} / \mathrm{min}$. As expected the system works in dilute phase given that the flow rate provided by the blower (see Table 5) is above the saltation flow.

Knowing the transport phase of the system it was time to start the pressure drop calculations using the dilute phase model. The mathematical model applied for this estimation was created from a function of pressure drop dependent on the volumetric gas flow (related to the blower inlet conditions according to the manufacturer) and the mass flow of sugar.

Figure 5 presents pressure drop for the pneumatic conveying system having for six different angular velocities of the rotary valve MPSH 22/22 (see Table 5), generating six different mass flow of sugar. Figure 5 also shows the theoretical curve of the positive displacement blower for both rotational speed offered by the variable frequency drive (4090 rpm and $4800 \mathrm{rpm})$. 


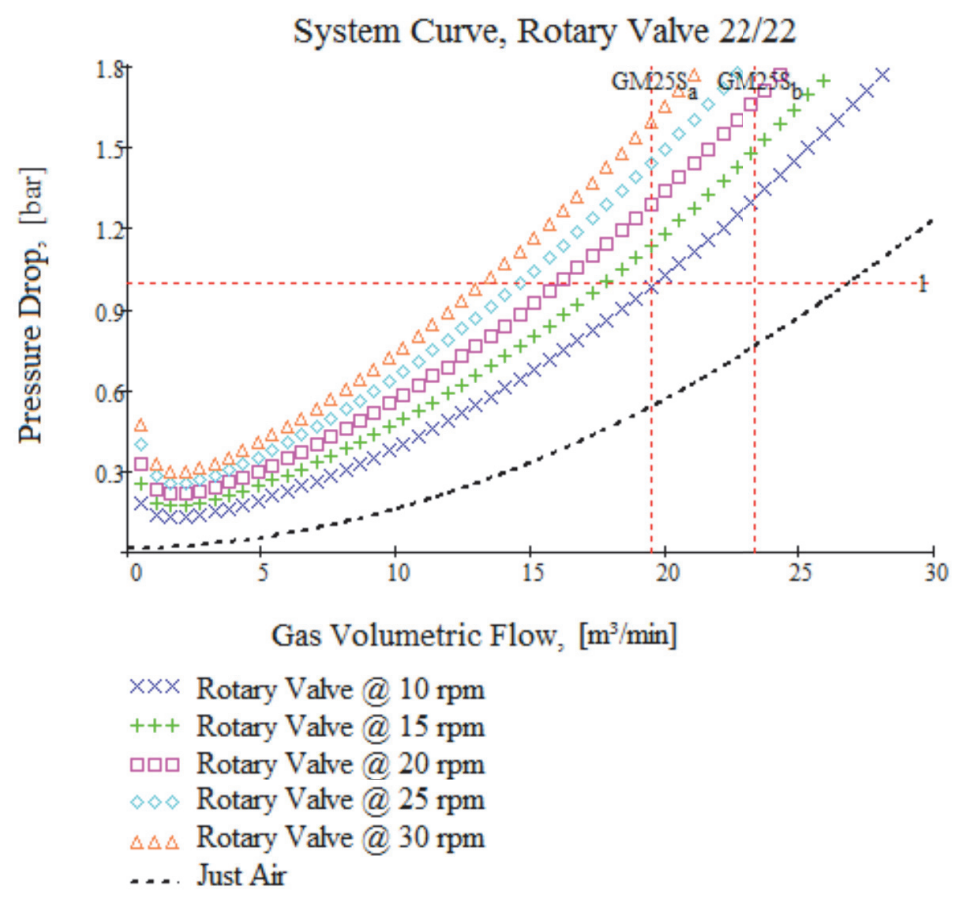

Figure 5 Phase diagram of the pneumatic conveying system

According to the model used, the sugar pumping system is working in most cases with a pressure differential greater than the operating point of the blower (1 (bar)). The only way that the blower can work on its operation point is if both the airlock 22/22 as the GM 20S Blower spins at its minimum speed, but in this case the sugar requirement is not satisfied. If the rotary valve spins at $20 \mathrm{rpm}$ (providing the requirement of sugar), the blower would need to overcome a pressure drop of about 1.3 (bar) and 1.7 (bar), respectively.

The consequences of the blower working outside its operating point are two. First the volumetric air flow is less than the theoretical (recirculation and friction losses), but this is not a dramatic problem because the saltation volumetric flow is quite low in comparison (between $2.0 \mathrm{~m}^{3} / \mathrm{min}$ and $2.4 \mathrm{~m}^{3} / \mathrm{min}$ ). The second consequence is that this produces a higher outlet temperature. A problem that can be dramatic for the pipe, since sugar must withstand elevated temperatures (above $130^{\circ} \mathrm{C}$ ), this can produce that the sugar caramelizes during transport, causing them to stick to the inner walls of the pipe, thereby producing a pressure drop even higher until the pipe is complete blocked. This is the reason for downtime of the production line. To solve the high temperatures in the pneumatic pumping system three solutions were suggested:

- Work both, the blower and the airlock, at their lowest rotational velocity.

- Increase the blower's velocity.

- $\quad$ Reduce on at least a $45 \%$ the pressure drop that the blower must overcome.

If the rotary valve works at its lower rotational speed the sugar requirement would not be met accomplish. Increasing the rotational speed of the blower would cause that outlet temperature decrease in at least $2 \%$, not much difference there and at the same time more 
velocity implicates more losses so the problem wouldn't be solved. The only potential solution is to decrease the pressure drop the blower must overcome. This suggests two solutions:

- Decrease the length of the pipeline and/or the number of accessories (valves, elbows, etc).

- Change the blower to one that works with a maximum of $13 \mathrm{~m}^{3} / \mathrm{min}$ volumetric flow rate.

The most viable solution in terms of costs would be to change the GM 25S blower Aerzen to one that handles a lower air flow rate. According to the mathematical model, if installed a blower that handles a volumetric air flow of $13 \mathrm{~m}$ ?/min (or less) and can be able to overcome a pressure gradient of 1 (bar), the system would work in optimal conditions for any speed of the lock $22 / 22$.

\section{CONCLUSIONS}

The calculation of the saltation volumetric flow is an important parameter for the analysis of the pneumatic conveying system because it helped determine the phase of transport and the ratio of volumetric gas flow where the transport would be in diluted phase.

The mathematical model used simulates correctly the behavior of solid-gas flow and its application allowed to determine without any doubt the cause of the obstruction of the pipeline in the pneumatic system. It was found specifically, that the blockage was the result of the high temperature at the blower outlet. A consequence of this high temperature the sugar caramelizes and it would stick to the walls of the pipe creating the obstruction.

\section{REFERENCES}

[1] Liang-Shih, F and Chao, Z. Principles of Gas-Solid Flow, Cambridge University Press, New York, United States of America, 1998, pp. 3-20, 461-468.

[2] Crowe, C. Multiphase Flow Handbook, Taylor\&Francis Group LLC, Boca Raton, United States of America, 2006, Chapter 4, pp. 1 to 50.

[3] Mills, D. Pneumatic Conveying Desing Guide, Elsevier Butterworth-Heinemann, Oxford, Great Britain, 2004, pp. 119-125.

[4] Brennen, C. Fundamentals of Multiphase Flow, Cambridge University Press, New York, United States of America, 2005, pp. 19-26.

[5] Van Wylen, G, Fundamentals of Thermodynamics, UG/GGS Information Services, Phoenix, United States of America, Sixth Edition, 2003, Apendix A, pp. 660.

[6] Saldarriaga, J, Hidráulica de Tuberías, McGraw-Hill, Colombia, 1998, pp.. 114-119.

[7] Crowe, C. Multiphase Flow Handbook, Taylor\&Francis Group LLC, Boca Raton, United States of America, 2006, Chapter 7, pp. 5, Table 7.1. 
